\title{
Voces, imágenes y escritos que rememoran el pasado: Metodología para la recuperación de la memoria histórica indígena del occidente de Panamá
}

\author{
Ana Sofía Solano Acuña \\ Universidad Nacional-Costa Rica \\ El Colegio de América, Centro de Estudios Avanzados para América Latina y \\ El Caribe (UPO)-España
}





\title{
Voces, imágenes y escritos que rememoran el pasado: Metodología para la recuperación de la memoria histórica indígena del occidente de Panamá
}

\section{Voices, images and writings that recall the past: Methodology for the recovery of the indigenous historical memory of western Panama}

\author{
Ana Sofía Solano Acuña \\ Universidad Nacional-Costa Rica \\ El Colegio de América, Centro de Estudios Avanzados para América Latina y El \\ Caribe (UPO)-España \\ ana.solano.acuna@una.cr
}

Fecha de recepción: 11 de diciembre de 2020

Fecha de aceptación: 10 de abril de 2021

\begin{abstract}
Resumen
En el presente trabajo se expondrá la experiencia metodológica desarrollada desde la Universidad Nacional de Costa Rica para aportar a la recuperación de parte de la memoria histórica del occidente de Panamá, específicamente de la población indígena Guaymí en el período de 1880 a 1925. Como se expondrá a lo largo de estas páginas, la reconstrucción de hechos, sujetos, ideas y procesos se ha llevado a cabo a través de una polifonía de voces, visiones y fuentes que permitan acercarse a este sector olvidado y desdibujado desde la historia nacional de estos dos países. Dicho período de investigación es de gran importancia pues propuso los cimientos para la relación que estos sectores poblacionales tendrán con el Estado, panameño y posteriormente costarricense durante todo el siglo veinte.
\end{abstract}

Palabras clave: Memoria histórica; Panamá; Guaymí; Diseño metodológico; Indígenas.

\footnotetext{
Abstract

This paper will present the methodological experience developed at the National University of Costa Rica, with the purpose of contributing to the recovery of part of the historical memory of western Panama, specifically about the guaymi indigenous population in the period from 1880 to 1925 . As it will be presented throughout
} 
Voces, imágenes y escritos que rememoran el pasado... - A.S. Solano Acuña

these pages, the reconstruction of facts, subjects, ideas and processes has been conducted through a polyphony of voices, visions and sources that allowed us to approach this forgotten and blurred sector in the national history of Panama, but also of Costa Rica. This period of research is of great importance, as it proposed the foundations for the relationship that these sectors of the population will have with the Panamanian State and, later, with the Costa Rican State throughout the twentieth century.

Keywords: Historical memory; Panama; Guaymi; Methodological design; Indigenous.

\section{INTRODUCGIÓN}

Este trabajo relata la historia de resistencia y violencia que la gente indígena del occidente de Panamá ha protagonizado desde los primeros años de la conquista española, y que marcó muy particularmente su relación con el poder en el período de 1880-1925. La gente Guaymí se localizó entre informes de misiones, pleitos y solicitudes al Estado, ellos y ellas son los ancestros de 9.543 personas que hoy día viven en Costa Rica (Instituto Nacional de Estadística y Censos, 2013) y de 285.033 sobrevivientes en Panamá (Instituto Nacional de Estadística y Censos, 2010).

Hoy día y a consecuencia de los hechos ocurridos en parte del período investigado, se cuenta con población en ambos países. En Panamá la mayor cantidad de población se encuentra en Chiriquí, Bocas del Toro, Veraguas, la Comarca Ngäbebuglé y la ciudad de Panamá. En Costa Rica en los poblados del cordón fronterizo y en cinco territorios indígenas reconocidos por el Estado (Abrojo Montezuma, Altos de San Antonio, Conte Burica, Coto Brus, Alto Laguna de Osa). En gentilicio con el que se han reconocido en los últimos años a través de sus luchas ha sido el de Ngäbes y Buglés, con lo cual ha ido quedando en el desplazamiento el de Guaymíes, sin embargo, para el período investigado las fuentes utilizan este último y el proceso de investigación es coherente con ello.

Tal como lo propone Arturo Taracena Arriola (1999), a través de la historia de una región podemos comprender no solo un fenómeno histórico local, sino que nos proporciona herramientas para analizar la construcción del Estado nacional y para entender el presente de proyectos nacionales en crisis.

El siglo XIX y el principio del siglo XX en el caso panameño fue un período sombrío para la investigación histórica de estos sectores de población, en parte por dificultades reales de acceso a documentación, pero principalmente porque no han sido sujetos centrales en la producción historiográfica panameña. Y es que preguntarse por los "no oficiales" siempre establece retos adicionales a la investigación, muchos de los cuales pasan por la propia deconstrucción de los imaginarios folklóricos, estáticos, a históricos y desarraigados del presente que se han ido consolidando sobre las sociedades indígenas en prácticamente toda la región centroamericana. 
Este trabajo pretende explorar la forma como el Estado panameño ha utilizado los conceptos de "mestizo", "cholo" e "indígena" heredados de la época colonial y cómo los redimensionó al entrar a la República, tanto en su paso por el proyecto colombiano como en su vida independiente. Todo lo anterior influido en gran medida por los discursos latinoamericanos del final del siglo XIX y las primeras décadas del siglo XX, sobre la representación de las etnias y los sujetos nacionales. Para este período, además, se tendió a criminalizar la lucha y las demandas indígenas, y se exacerbó el tratamiento de "frontera salvaje" para referirse a sus espacios vitales donde el Estado no tuvo o poseyó presencia de forma limitada. Tal como sucedió en otras partes del continente, la perduración de las llamadas "fronteras interiores" resultaba entonces contradictoria con la idea de integridad del Estado (Roulet y Navarro, 2005).

Como en otras experiencias de América Latina, la violencia en Panamá se ha instaurado como un mecanismo legítimo del Estado para administrar a las poblaciones indígenas. El mismo se concibe como un proyecto siempre incompleto que debe ser constantemente enunciado e imaginado, invocando lo salvaje, lo vacío y el caos que no sólo yace por fuera de los límites de su jurisdicción, sino que además es una amenaza desde dentro (Das y Poole, 2008).

Como lo plantean Ronald Soto y David Díaz (2006), al realizar este tipo de análisis es posible reconstruir la génesis de cómo lo indio fue incluido, excluido, invisibilizado, redimensionado y operacionalizado por los políticos e intelectuales y a su vez se puede detallar el papel que los discursos sobre el mestizaje, la desindinización y la ciudadanización jugaron en esos procesos.

Etnia y raza agregan tintes multicolores a la de desnudez de las relaciones de explotación. La variedad es un resultado innegable de la historia; legados de las culturas precolombinas y del poblamiento afroamericano de la costa caribe desde el siglo XVII. Pero todas son culturas sometidas, alienadas, con las raíces rotas. Y en esa imposibilidad de lograr una identidad cultural total reside, precisamente, uno de los rasgos más sutiles de la dominación. Más allá del exotismo, esa amplia gama de culturas ha permitido que la dominación se sirva del prejuicio como una máscara que oculta y justifica la situación de inferioridad de la inmensa muchedumbre de los de abajo...La exclusión de indios y negros fue una invariable regla social. Ésta encontró eco, hasta bien entrado el siglo XX, en muchas medidas de segregación (tácitas o expresas) y en no pocas prohibiciones (Pérez Brignoli, 2010, p. 26-27).

Este contexto tuvo como fin último desmembrar a las sociedades indígenas, expoliando elementos esenciales para su reproducción física y simbólico-política como su territorio y sus formas de gobierno. El discurso de la necesidad de ciudadanizar al indio para encontrar el progreso y conformar una sola nación, contribuyó a la privación de derechos individuales y colectivos, así como el ingreso en la estructura social donde el equilibrio entre deberes y derechos no fue proporcional. 
Voces, imágenes y escritos que rememoran el pasado... - A.S. Solano Acuña

Para dimensionar las fuentes y comprender los procesos, fue necesario como primera tarea entender la relación de los procesos de identidad de estas personas (y tienen) con el espacio geográfico dado que este es el pilar para la habitación, el sustento y la reproducción física y cultural. Según Barabas (2008), el control e identificación territorial lleva consigo implicaciones directas sobre los procesos de construcción étnica, pues amarra un presente indígena con un pasado, con los ancestros, con la génesis misma de su pueblo.

Hay una referencia a la "memoria histórica" cuando se traza el objetivo de rescatar del silencio y el olvido hechos dolorosos de la historia reciente y no tan reciente. La memoria es la vida con capacidad de ser absoluta y la historia es la reconstrucción, siempre problemática e incompleta, de lo que ha sucedido. En América Latina, muchos de los procesos de memoria sean estos "oficiales o subalternos", están marcados por un hecho traumatizante que hace del proceso de memorizar un hecho político en sí mismo (Jelin, 2002). Los olvidos, silencios y elaboraciones cuando no son orquestadas por el Estado, son decisiones paliativas, procesos de sanación, pero raramente olvido.

Es común que los acontecimientos traumáticos marcados por la represión y la disgregación social conlleven grietas en la capacidad narrativa, huecos en la memoria, o elementos sin explicación. El olvido y el silencio son intersubjetivos, no tienen necesariamente relación con la existencia o falta de recuerdos almacenados, saberes guardados, informaciones archivadas en registros y centros de documentación públicos y privados, más bien su relación radica en la posibilidad de ser usados y trabajados por los sujetos.

Los avances que aquí se presentan son el resultado de un proceso de pesquisas, organización y sistematización de fuentes documentales desde el año 2012 cuando inicié mis estudios de Maestría y Doctorado en la Universidad Pablo de Olavide (Sevilla-España). Antes ya me había acercado a la población desde una mirada diferente, la que ofrece el trabajo etnográfico propio de la Antropología. Las preguntas de investigación que surgieron, surgen y surgirán son el resultado de ese ir y venir del pasado al presente, y de la observación en primera línea de la falta de investigación e interés que ha suscitado esta sociedad indígena, así como las frecuentes explicaciones del presente sin profundidad histórica que abundan en ambos países.

Posterior a este proceso de formación que culminó en el año 2019, se abre en forma paralela una línea de investigación en la Universidad Nacional de Costa Rica bajo mi coordinación, la cual busca dar continuidad a los procesos de investigación que permitan comprender la situación actual de esta población indígena, así como los fenómenos poblacionales y culturales compartidos entre Costa Rica y Panamá. Si bien la línea de investigación continúa trabajando el período de 1880-1925 se considera fundamental lograr un modelo que incluya la mirada de la violencia en la 
larga duración, con una caracterización de sus perpetradores, de los intereses y de las formas de resistencias.

Así mismo es importante resaltar que al ser un proceso de investigación desarrollado desde una universidad pública, se busca responder a la misión de la Universidad para la incorporación de este tipo de debates con el objetivo de "formalizar acuerdos y concertar acciones institucionales tendientes a lograr el bienestar social y el desarrollo nacional como una responsabilidad inherente a su condición de instituciones públicas" (CONARE, 2016, p. 79).

Además, este proyecto de investigación posee la intensión de alinearse con los mandatos internacionales que buscan el reconocimiento y la recuperación de la memoria de sectores poblacionales históricamente excluidos, entre ellos la Conferencia Mundial de Población y Desarrollo realizada en Cairo en 1994, la Convención sobre la Eliminación de todas las Formas de Discriminación contra la Mujer (CEDAW) de 1979, el Convenio No 169 de la Organización Internacional del Trabajo sobre Pueblos Indígenas y Tribales de 1989, la Conferencia Mundial contra el Racismo, la Discriminación Racial, la Xenofobia y las Formas Conexas de Intolerancia realizada en 2001 en Durban, y la Declaración de las Naciones Unidas sobre los Derechos de los Pueblos Indígenas de 2007.

\section{LA REGIÓN Y EL PERÍODO DE ESTUDIO.}

La región que aquí se comprende como occidente de Panamá a finales del siglo XIX, estuvo compuesta por lo que hoy son las provincias de Chiriquí, Bocas del Toro y Veraguas, así como la parte centro-oeste de Coclé (Ver Mapa 1).

La documentación testimonia un imaginario "deshistorizador" del territorio, es decir, desde las interpretaciones, apreciaciones, descripciones se sugiere que el oeste del país no poseía una historia cultural y, por el contrario, se invitaba a construirla. La idea de "espacio vacío" convive y compite con la de "espacio salvaje" y es posible rastrearlos en prensa, documentación oficial y escritos de intelectuales. Es así como, tras la historia nacional, es necesario develar la historia regional occidental y la historia étnica en particular, ambas absorbidas por discursos homogeneizantes y totalizadores donde la polifonía de las voces disidentes ha sido borrada.

Pablo Serrano (2002) plantea, que de manera paralela a los principios de la identidad nacional forjada por los liberales desde el siglo XIX, surgió una especie de "centralismo historiográfico" que negó lo heterogéneo y diverso, lo realmente existente en el nivel local y regional, para crear y justificar la creación de las historias nacionales, como síntesis de las nacientes identidades nacionales de la región latinoamericana. La región occidental de Panamá es una realidad cambiante $\mathrm{y}$, además, producto de la dinámica socioeconómica; a la vez, integra espacios sociales y lugares vividos con una especificidad que le otorga una estructura propia, 
Voces, imágenes y escritos que rememoran el pasado... - A.S. Solano Acuña

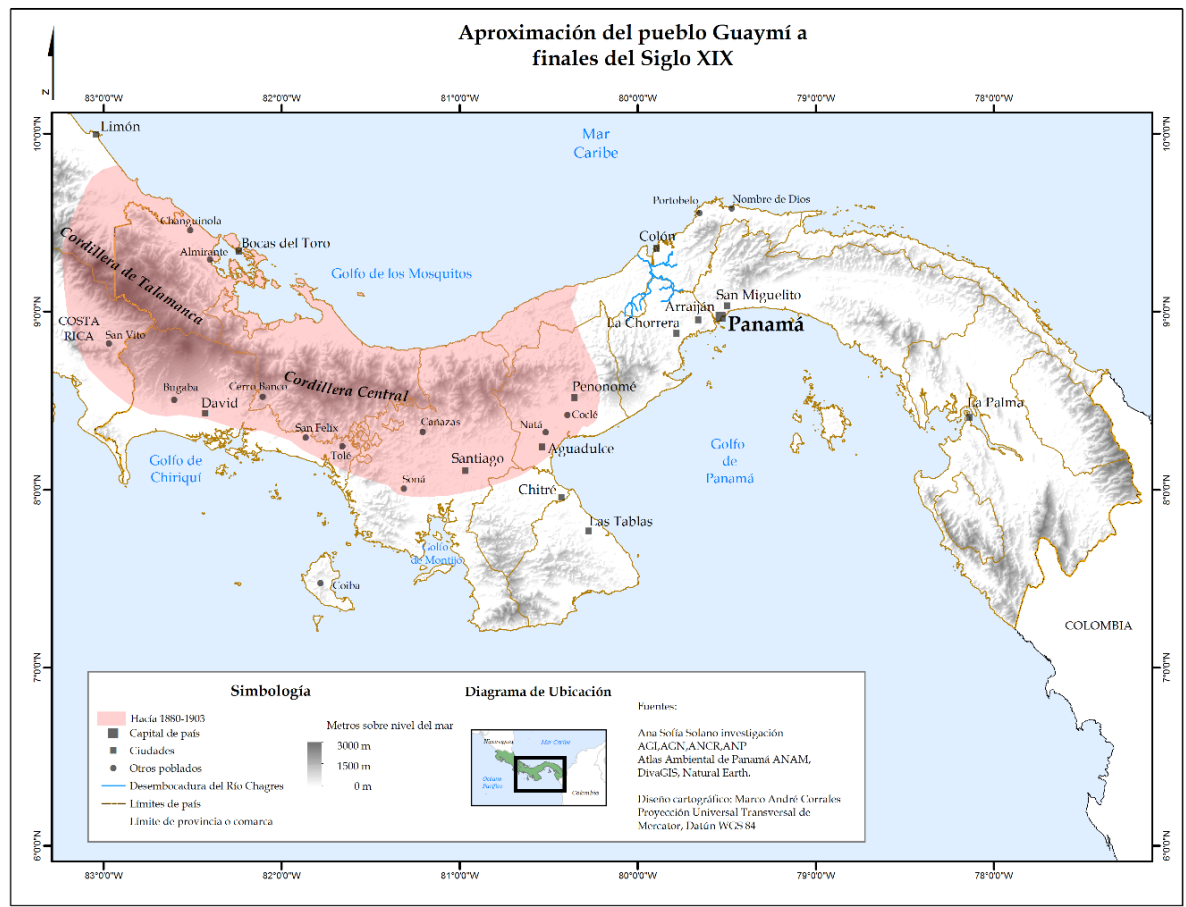

cuya construcción culminó con las representaciones erigidas a partir de imágenes regionales, por parte de los vecinos y de los "extranjeros".

Existen muchas posibilidades para definir la región occidental de Panamá, desde dentro o desde fuera. Esto en parte a su ubicación estratégica y a las interacciones sociales y culturales que en ella se han dado. Pero cabe destacar, el occidente tanto en el pasado como en el presente no es solamente un punto de unión entre Centroamérica y Panamá, sino más bien un espacio donde se reconfiguran identidades de todo tipo, una de las más importantes la étnica.

Gerhard Sandner (1981) planteó que, en el caso de Panamá después del goldrush y del poblamiento de California posterior a 1848, el istmo se convirtió en un espacio de tránsito "intra americano" y en una grieta-conexión entre México, Centroamérica y Suramérica. Para el siglo XIX hay una política de penetración del istmo centroamericano de parte de potencias lejanas, particularmente de los Estados Unidos. Zonas consideradas en el pasado como periféricas del poder español y del control republicano, en los primeros años del siglo XX, van a convertirse en nuevos espacios de extracción de riquezas, conllevando nuevas formas de explotación y de relación con las poblaciones ahí asentadas.

La importancia del istmo de Panamá dentro de este escenario justificó el organizar todo dentro y fuera para "blindar" los intereses extranjeros. El encuentro 
entre la estructura colonial heredada en la economía y la economía global orientada hacia el capital a finales del siglo XIX transformó la organización del trabajo, la economía de subsistencia irrumpió en las organizaciones de tipo étnico-territorial, en los procesos de identidad y reconocimiento político étnico, en la legislación nacional, solo por citar algunos impactos. Se entró además a una revaloración del espacio nacional, primero colombiano y luego panameño, donde los espacios de poco valor empezaron a ser requeridos con cierta urgencia como parte de proyectos nacionales con raíces en la economía extranjera. Parte de la necesidad de incorporar esta porción del territorio también se dio por la trayectoria de iniciativas separatistas de las que se puede tener testimonio en la documentación de esta época, así como los yacimientos de carbón y las minas de oro.

El mecanismo de movilizar e implantar nuevas poblaciones en espacios de difícil control no es nuevo, fue una estrategia utilizada desde los tiempos de control español pero que en el siglo XIX es retomado con la finalidad de "romper el territorio" y hacerse de mano de obra menos resistente al sistema. Según Santana Cardoso y Pérez Brignoli (1999, p.175), tanto los liberales como los conservadores poseían visiones de la tierra y las poblaciones, disímiles en cuanto las estrategias de explotación, pero coincidentes en los resultados, ambos bandos "no trajeron reforma alguna a la masa de la población, a los campesinos de subsistencia, trabajadores del campo o indios, sino un empeoramiento muy drástico".

El conflicto entre la Nueva Granada, posteriormente Colombia, y finalmente Panamá con Costa Rica es otro de los elementos, definitorios de la necesidad sobre incorporar esta parte del territorio a los planes económicos y políticos. Costa Rica por un largo período tuvo y perdió parte día territorio occidental de Panamá y se realizaron varios intentos de arbitraje para definir los límites, tensión que desató la Guerra de Coto en 1921. El capital extranjero se movió en este escenario y es así como United Fruit Company no solo se asienta, sino se expande entre ambos países y agita la política de ambas naciones.

Para esta época se constituye un mercado de tierras, es decir, existían porciones de tierra adecuadas para la producción para la exportación y las cuales se encontraban inmovilizadas. Estas tierras pertenecían a órdenes religiosas, comunidades indígenas, eran tierras públicas, entre otras; todas las condiciones fueron trasgredidas para que ingresaran al mercado y se encaminarán a un proceso de privatización. En Panamá abundan los ejemplos donde se utiliza la tierra como una forma de pago del Estado y una garantía para la inversión en obras públicas como el ferrocarril y el mismo Canal Interoceánico.

En 1850 los estadounidenses pretendieron llevar a cabo un proyecto de repoblamiento en el oeste de Panamá, aunque fallido, materializó no solo los intereses económicos en la región, sino las estrategias de administración de poblaciones, para lo cual los intereses estadounidenses no tenían problema en "echar mano". La propuesta consistía en movilizar población negra al sur de Chiriquí para explotar 
Voces, imágenes y escritos que rememoran el pasado... - A.S. Solano Acuña

los yacimientos de carbón con el fin de provisionar barcos y poseer colonias para la comunicación en la ruta que conectaba con Centroamérica por tierra.

Para ese mismo año, la compañía francesa Compagnie du Golfe Dulce obtuvo un contrato para ubicar colonos en el Golfo Dulce, construir un canal y un ferrocarril desde Bocas del Toro hasta el Golfo, el cual tampoco se llevaría a cabo. Un año después muchas personas sí se trasladaron hasta allá, pero poco tiempo después abandonaron el lugar. El contrato fue transferido a la inglesa Costa Rica AtlanticPacific Junction and Colonization Company, que renunció 3 años después por los problemas limítrofes entre Costa Rica y la Nueva Granada (Sadner, 2003).

En 1848 hubo una concesión para un tren de Stephenson y Aspinwall (hoy Colón) que se terminó en 1855; en ese mismo año hay una primera concesión de Canal no realizada. Para el año de 1858, Colombia era una República Federal, primero bajo el nombre de Confederación Granadina y después como Estados Unidos de Colombia, regida por sendas constituciones de corte federalista.

La Constitución de 1863 conocida como Constitución de Rionegro, aplicó de manera extrema los principios liberales. Por una parte, concedió mucha autonomía a los Estados, otorgó libertades de prensa, empresa, asociación, porte y comercio de armas, movilización hacia dentro y fuera del país y proclamó un estado laico, lo cual no fue del todo bien recibido en un país con una amplia mayoría católica. Además, abolió la pena de muerte y redujo el poder de la rama ejecutiva, limitando el período presidencial a dos años y otorgándole casi todas las facultades de gobierno al Congreso.

En 1880 se da la primera palada para el Canal Interoceánico, el cual presentará algunos problemas en 1887 y posteriormente, en 1889 la compañía se retira. En 1894 la Compagnie Nouvelle du Canal de Panamá retoma contrato e inicia en 1895. Y finalmente, en 1903 mediante el tratado Hay-Bunau Varilla, entre Estado Unidos y Panamá, se potencia la separación de Colombia y establece privilegios a los Estados Unidos.

El período comprendido entre 1869-1914, estuvo determinado por políticas de intervención norteamericana con el objetivo de implantar un régimen de administración canalera, pero también hubo intervención extranjera para la explotación de productos como el guano (Ibid, 2003).

Con este marco fue un período convulso de repetidas protestas en Colombia por los rumbos tomados en materia económica. El separatismo es recurrente. Hay intentos en 1830, 1840 y 1850, y no faltan llamados al protectorado inglés y norteamericano. El Tratado de Paz, Amistad, Navegación y Comercio, celebrado entre Colombia y los Estados Unidos en 1846, establece la neutralidad del istmo y garantiza el libre tránsito.

En 1855 Panamá se convierte en Estado Federal, situación que es reiterada en la Constitución colombiana de 1863 . El istmo no puede ser ajeno a los conflictos 
internos con Colombia. En 1885 la guerra civil se extiende por todo el país, y los Estados Unidos intervienen para garantizar el orden. Al modificarse la Constitución colombiana, Panamá pierde toda autonomía. Una situación parecida ocurre en 1900, durante la "Guerra de los Mil Días". Los Estados Unidos vuelven a intervenir Panamá. La independencia y las negociaciones del tratado canalero son por entero paralelas en 1903. De hecho, todo ocurre bajo la protección de la marina norteamericana (Pérez Brignoli, 2010).

El 8 de agosto de 1885, el presidente Núñez declaró en un discurso desde el balcón del Palacio de San Carlos, que la Constitución de 1863 "había dejado de existir" pues el país no aguantó una Constitución tan liberal y muchos eran los intereses puestos en peligro. Se inicia así la llamada Regeneración. El movimiento regenerador impulsó una serie de reformas resultando en la convocatoria a una asamblea de delegados para redactar una nueva carta política. Se establecieron las bases para el regreso a un modelo de Estado proteccionista, donde el gobierno central, nuevamente dotado de amplios poderes de los cuales había sido privado, era el responsable de la política económica del país en materia de importación y exportación, así como del control bancario y el establecimiento de impuestos y aranceles. En materia administrativa, los estados se convirtieron en departamentos. Las intendencias y comisarías son regidas desde la capital, con gobernadores, alcaldes, e intendentes nombrados por el Presidente. El período presidencial se aumentó a seis años, y se dotó de toda clase de facultades al poder ejecutivo. La pena de muerte fue restablecida, y tuvo plena vigencia hasta la reforma constitucional de 1910.

Se restituyeron los privilegios y bienes incautados de los cuales gozaba la Iglesia Católica, regresaron las órdenes que habían sido expulsadas y se les encargó la labor de impartir la educación y vigilar las fronteras. El Concordato de 1887 no será sino la consecuencia lógica de la nueva carta constitucional; resultando en algunas convenciones adicionales como el Convenio de Misiones y lo relativo al registro civil, a los cementerios y al fuero eclesiástico y episcopal. Este fuero difería las causas civiles y criminales de los clérigos a los tribunales civiles de segunda instancia y establecía para ellos un tratamiento de respeto; en cambio, los de los obispos quedaban reservados a la Santa Sede. Además, se abrieron las puertas para la llegada de nuevas comunidades religiosas que promovieron la labor misionera. En esta época la doctrina de mestizaje en América Latina es claramente una maniobra estratégica discursiva.

La preocupación fue lograr "homogeneizar" a la población de orígenes variados para poder encaminarse al progreso y lograr la unidad nacional. Estas ideas implicaron una percepción negativa de las identidades étnicas, las cuales se veían como un obstáculo para la consolidación del Estado y del modelo cultural definido como "lo nacional". Se exaltó la imagen del mestizo como prototipo y se promocionó la inferioridad del indígena, lo cual se concretó en la consolidación de un mapa geográfico racial del territorio nacional. Este pensamiento será el cimiento 
para una estrategia nacional fundada en la desindianización de la población, la cual se tradujo en políticas sobre la congregación y la castellanización en el Panamá de la época. El objetivo de este pensamiento era liberar (al menos discursivamente) a los indígenas del pasado colonial, para reinsertarlos en un modelo de dominación similar, pero ahora con obligaciones de ciudadanos, de segunda, pero ciudadanos al fin. Luego de la sangrienta Guerra de los Mil Días, el 4 de noviembre de 1903 en Cabildo Abierto y por iniciativa del Concejo Municipal del distrito de Panamá, se proclamó la separación de Colombia. Seguidamente algunos meses después, la zona del Canal fue entregada a los Estados Unidos el 19 de mayo de 1904 (Pizzurdo Gelós y Aráuz, 1996).

Los límites definitivos entre la Zona del Canal y la República de Panamá se establecieron por la Convención del 2 de setiembre de 1914. No obstante, implicó el sacrificio de algunos pueblos dentro de la Zona, como fue el caso de Limón, situado en el área del Lago Gatún, lo que motivó las protestas de los pobladores al verse desalojados de sus tierras y propiedades. Otros pueblos sacrificados también fueron: Mindí, Gorgona, Gatún y Chagres (Ibid, 1996).

Durante la primera administración del Doctor Belisario Porras (1912-1918) se promovió el establecimiento de familias migrantes europeas trabajadoras del canal en Colonias Agrícolas, en Chiriquí. Las mismas sumaban aproximadamente 200, y tenían más de 17 de años de residir en Panamá; su incorporación implicaba una inversión del Gobierno a manera de préstamo por 100.000 balboas que se devolverían en contratos flexibles. Sin embargo, en esta oportunidad no se concretó, pero se retomaría la idea en los procesos de construcción de los ferrocarriles de penetración en Chiriquí y Los Santos. Estas penetraciones fueron acompañadas por miles de hectáreas cedidas, lotes baldíos e indultados a través de contratos con inversionistas extranjeros (Ibid, 1996).

Hacia 1912, el gobierno de Belisario Porras emitió una legislación siguiendo el camino de sus antecesores para la "civilización" de los pueblos indígenas, con la finalidad de integrarlos, asegurar el espacio nacional y la construcción de una nacionalidad donde lo indio tomará relevancia solamente como parte del pasado. Esto será en gran medida el antecedente de la Revolución Tule de 1925. Para el año de 1918 se da la ocupación de tropas norteamericanas en Chiriquí, aludiendo que la zona se encontraba tomada por el cuatrerismo y que los ciudadanos norteamericanos y sus bienes, se encontraban en peligro.

El 21 de marzo de 1921 Costa Rica invade Pueblo Nuevo de Coto, situado en el área de larguísima disputa primero con Colombia y luego con Panamá, en la provincia de Chiriquí. A pesar de que Costa Rica sufrió una importante derrota, la República de Panamá se vio obligada por el Gobierno de los Estados Unidos, a ceder parte del territorio en disputa por los intereses sobre las tierras para la explotación bananera y por el temor de que los británicos afianzaran su influencia en la explotación de petróleo del lado costarricense. 
En 1925, la Revolución Tule tuvo como objetivo la proclamación de la República de Tule, lejos de ser lo que algunos investigadores han descrito como un hecho exótico más a recordar para aquella época; fue el resultado de las continuas presiones y arbitrariedades de la Policía Nacional hacia la población para "civilizarla" y a su vez parte de la estrategia norteamericana de ganar adeptos estratégicamente ubicamos. A este escenario se sumó la llegada de compañías norteamericanas (The Vaccano Bross-United Fruit Co), quienes mediante su instalación usurparon tierras en la Bahía de Mandinga y en Armila y destruyeron los cultivos indígenas. Luego de 26 días de deliberación el Congreso de Ailigandí emite la "Declaración de Independencia y derechos humanos del pueblo de Tule de San Blas y Darién" el 12 de febrero de 1925 (Howe, 1996).

\section{UNA METODOLOGÍA PARA ENTENDER EL PASADO.}

El gran valor de un proceso investigativo debe radicar en lo que abona para una imagen menos distorsionada de las múltiples realidades sumergidas en una Nación. Es por eso que, desde esta línea de investigación, se parte de que las investigaciones históricas y antropológicas lejos de ser "prácticas exóticas" son testimonios del presente complejo, cuestionando los abordajes folklóricos, poco documentados, y con interpretaciones complacientes hacia grupos de poder o intereses económicos.

Como se ha indicado páginas adelante, el estudio del período escogido, la región y la población presentaba varios retos, el primero de ellos fue la carencia de investigaciones históricas anteriores de las cuales echar mano en las primeras etapas de problematización. En ese sentido fueron la antropología y la arqueología las que brindaron textos base, preguntas base para iniciar el proceso de diseño y criticidad de las ausencias.

Otra de las dificultades reales al estudiar cualquier tema concerniente a Panamá en el siglo XIX, es la dispersión de las fuentes las cuales depende del tema investigado puede encontrarse en varios países y archivos. En cuanto a las fuentes documentales también se debe de trabajar con el inconveniente una anticuada administración, principalmente en Panamá donde incluso no se tiene acceso a importantes fondos como los de la Iglesia Católica, y el extravío de documentos es cosa común.

En cuanto a la confiabilidad de los textos escritos y orales, se realizó el proceso de crítica de la fuente hasta donde se ha hecho posible y en las condiciones requeridas para cada tipo. En ambos casos, gran parte de lo indagado han sido representaciones, creencias e interpretaciones sobre el territorio, sobre las sociedades indígenas, sobre la convivencia.

Se establecieron cuatro familias de fuentes (Diagrama 1), para establecer un "control" sobre cada una de ellas ha sido indispensable conocer los alcances y limitaciones, el contexto de generación, el tipo de datos que brinda y poder mediante 
la triangulación realizar una adecuada conclusión de un hecho, episodio, intensión, o representación. Es así como se asume el proceso de investigación con un universo amplio de fuentes, pues hay que recordar que, al buscar a poblaciones subalternas, en muchas ocasiones las referencias pueden ser pequeñas o fragmentadas por lo que es necesario crear un acervo de información robusto a través de revisiones documentales y orales de espectro amplio.

Diagrama 1. Estrategia metodológica propuesta para la recuperación de la memoria Guaymí en el período investigado.

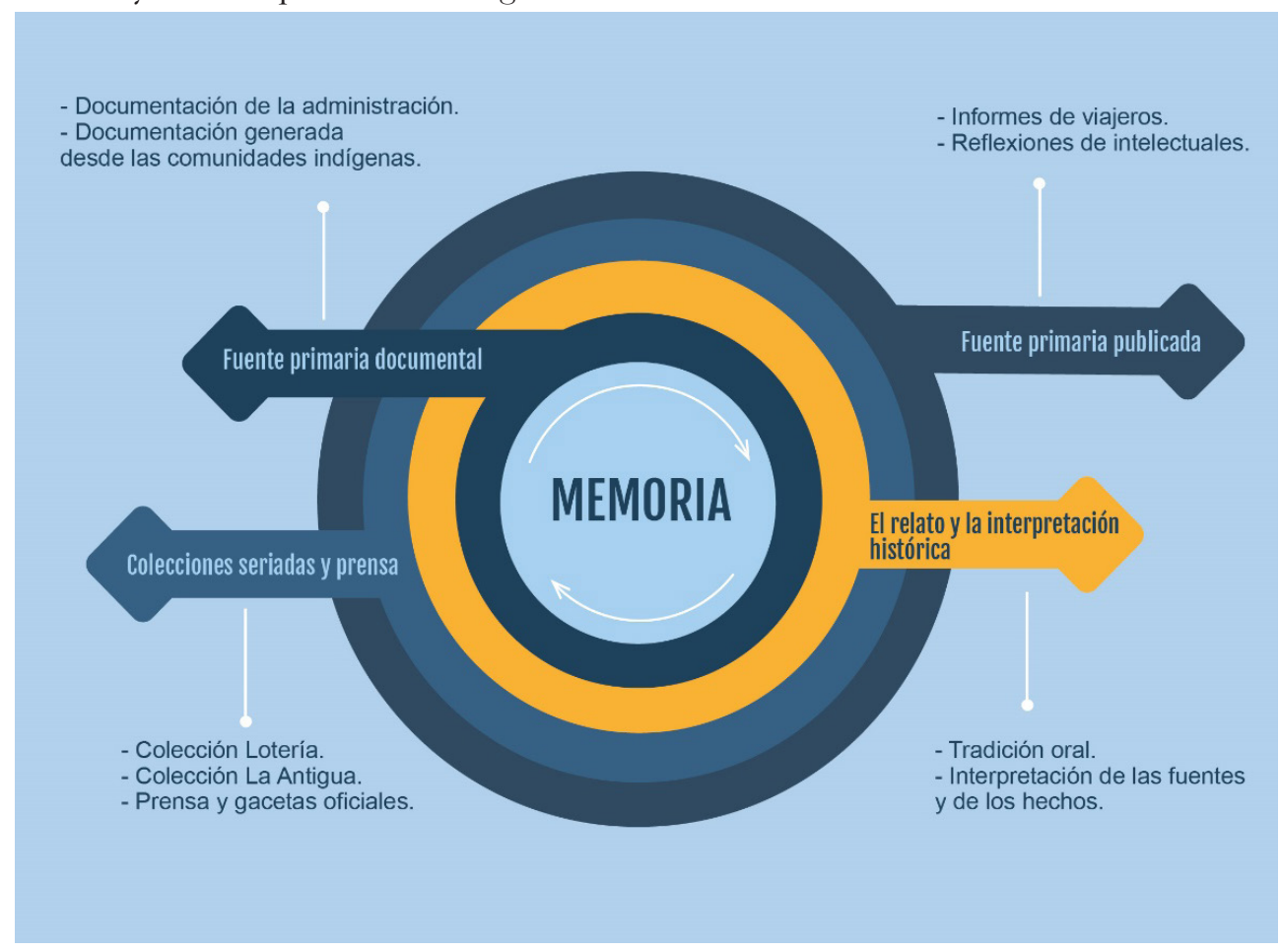

Fuente primaria documental (española, colombiana, panameña)

En el Archivo General de Indias (AGI), la pesquisa tuvo como objetivo ubicar en el período español, expedientes, pleitos, solicitudes, informes de visita que me permitieran recuperar la importancia y las dinámicas sociales del occidente de Panamá para esta época. Aún cuando esta temporalidad no es el objetivo de la línea de investigación, se considera de vital importancia comprender la representación del espacio y la población en la larga duración, esto porque muchas de estas imágenes van a continuar en el período investigado. Los documentos localizados en este archivo tienen un alto potencial etnográfico, estrategias de pacificación, administración de 
bienes, tierras y personas, entre otros. Igual situación la documentación ubicada en el Archivo General de Simancas (AGS).

En el Archivo General de la Nación (AGN) en Bogotá, el acervo documental es sumamente basto, sin embargo, cuando revisé fue a manera de contextualizar algún documento panameño o tratar de mirar un proceso de forma más regional. Dentro de la documentación examinada sobresale documentación de la Gobernación de Panamá, libros de visitas, comercio ilícito, causas por desafecto al gobierno, entre otros.

En cuanto al Archivo Nacional de Panamá (ANP) ha sido sin duda el que más información ha brindado al problema de investigación, la temporalidad y la población de estudio. Este archivo carece de una base de datos para la ubicación de material, sea está impresa o digital. Solamente se cuenta con algunos libros bastante desactualizados e incompletos con unas brevísimas descripciones iniciales, los mismos no cuentan necesariamente con un orden cronológico, faltan algunos tomos y la documentación esta poco tratada a nivel de conservación.

El período de 1880-1903 se encuentra mucho mejor descrito, en comparación con el período de 1904-1925, esto llama la atención pues durante el período republicano, y a pesar del surgimiento del archivo como institución en esos mismos años (1912), el interés por documentar la historia más allá del Canal de Panamá, fue cada vez menor.

La documentación que se encuentra en Panamá fue emitida por diferentes fuentes, de autoridades indígenas hacia autoridades colombianas o panameñas, de civiles indígenas (gente del pueblo) hacia autoridades colombianas o panameñas, en muy pocas ocasiones de las autoridades hacia la población indígena, aunque hay algunos casos. También es posible ubicar comunicaciones de autoridades o civiles indígenas hacia representantes de la iglesia católica, de alguna autoridad o funcionario colombiano hacia alguna autoridad o funcionario panameño, del gobierno central de Panamá hacia un funcionario comarcal o indígena, entre otros.

Sobresale también documentación emitida entre gobiernos como el de Costa Rica y Estados Unidos con Colombia y posteriormente con Panamá, para temas específicos, entre ellos, los límites fronterizos. En general, los documentos más abundantes son cartas, informes de visitas (de religiosos, prefectos y gobernadores), pleitos, informes sobre recaudación de impuestos, informes técnico-administrativos, y nombramientos o ceses de funcionarios.

\subsection{Fuente primaria publicada}

Para la investigación fue de gran relevancia tener acceso a documentos a través de publicaciones que se realizaron en su mayoría en la primera mitad del siglo XX. Aquí sobresalen algunos informes de exploración del occidente panameño en el período español que brindan detalles geográficos, etnográficos e ideológicos de la 
Voces, imágenes y escritos que rememoran el pasado... - A.S. Solano Acuña

época con respecto a esta parte del istmo y la población indígena mismo que se encuentran en la "Colección de documentos inéditos sobre la geografía y la historia de Colombia” (Tomo I) de Antonio Cuervo impresa en Bogotá en 1891.

Sobre esta misma línea se consultó "Jeografía física y política del Estado de Panamá” de Felipe Pérez, la cual se imprimió en Bogotá-Colombia 1862; así como la "Memoria sobre la geografía, física y política de la Nueva Granada" y "Compendio de geografía general. Política, física y especial de los Estados Unidos de Colombia" escritos por Tomás Cipriano de Mosquera en 1852 y 1866 respectivamente.

En materia de información etnográfica resaltan los aportes de Orlando Roberts quién, en 1817, convivió entre los indios valiente de Bocas del Toro, lo cual le permitió brindar detalles sobre la forma de vida, la organización política, y la relación con los ingleses y españoles. Henry Pittier a través de la "Primera contribución para el estudio de las razas indígenas de Costa Rica" publicada en San José en 1897, ofreció algunos detalles sobre la vida de esta población indígena. En 1882 y en 1892 Alphonse Pinart explorador, etnólogo y lingüista francés brindó a través de sus trabajos "Noticias de los indios Guaymíes y de sus costumbres" y "Vocabulario castellano-guaymí. Dialectos move-valiente, norteño y Guaymí penonomeño" respectivamente, de las más completas descripciones sobre características culturales de los indios Guaymí, además de uno de los primeros esfuerzos de documentación y clasificación de las lenguas indígenas del occidente de Panamá.

En 1888 y 1892 Soledad Acosta de Samper a través de sus trabajos "Historia del Istmo de Panamá" y "Descripción del istmo de Panamá en el siglo XVI", permite conocer las representaciones de cierta ala de la sociedad colombiana con respecto a Panamá y a la población indígena.

El zoólogo, explorador, inventor, ilustrador y autor estadounidense Alpheus Hyatt Verrill dejó como legado las notas etnográficas sobre los indios Guaymí más completas de los primeros años del siglo XX. El trabajo de Verrill fue sin duda la columna vertebral para poder comprender la dinámica cultural, territorial, étnica, comercial e ideológica de la sociedad indígena del occidente de Panamá. El historiador, periodista, novelista, cuentista y educador panameño Manuel María Alba Carranza en su obra "Etnología y población histórica de Panamá" editada en 1928, realiza un bosquejo sobre los pueblos indígenas y en el caso particular de los Guaymí los distancia de los "Bogotá" que se encontraban a orillas del río Calovévora.

Narciso Garay en 1930 en su trabajo "Tradiciones y cantares de Panamá: ensayo folklórico" también ofreció algunas líneas para rescatar manifestaciones culturales de los indios de Chiriquí. Frederik Johnson a través de su escrito "The Caribbean Lowland Tribes The Talamanca Division" de 1948 ofrece detalles de especial relevancia sobre la vida económica, las actividades de subsistencia, los poblados y la dinámica doméstica. 
Otro de los énfasis en que los viajeros y científicos hicieron grandes aportaciones a este trabajo fue en la recuperación de las representaciones del sector indígena del occidente en el relato histórico nacional. Aquí resaltan los trabajos de William Bollaert en 1860 "Antiquarian, Ethnological, and Other Researches in New Granada, Equador, Peru and Chili" y 1863 "On the Ancient Indian Tombs of Chiriquí in Veraguas (South-West of Panama), on the Isthmus of Darien"; así como y Carl Bovallius en 1883 con libro "Viaje por Centroamérica 1881-1883" donde se ocupan de la arqueología de esta parte del istmo y la debilitada relación con el presente etnográfico.

También gozan de una riqueza de detalles aquellos trabajos que se ocuparon de reflexionar sobre el papel del Estado y de los indígenas, y proponer algunas medidas paliativas al "problema" de la diversidad. En esta categoría se distinguen Ernesto Restrepo Tirado en 1892 con "Estudios sobre los aborígenes de Colombia" y ya para la época de la República Mateo Arauz con el "El problema indígena de Panamá" editado en 1926, así como Jephta Duncan con su obra "La Nación y las escuelas" del año de 1929.

Los trabajos que abordaron el problema de límites entre Costa Rica y Colombia también fueron de un gran valor entre ellos "Colección de documentos para la historia de Costa Rica. Documentos especiales sobre los límites entre Costa Rica y Colombia", León Fernández del año 1886; e "Historia de la jurisdicción territorial de la República de Costa Rica, 1502- 1880" Manuel María de Peralta del año 1891. Con respecto a la Guerra de los mil días fueron de gran valor las reflexiones y las memorias publicadas por algunos de sus protagonistas, entre ellas "Recuerdos de la guerra de 1899 a 1902" de Domingo de la Rosa del año 1938, "Ensayos, documentos y discursos" de Eusebio Morales del año de 1928, entre otros.

\subsection{Colecciones seriadas y prensa}

Como colecciones completas organizadas y consultadas se contó con la colección de la revista "Lotería" emitida por la Lotería Nacional de Beneficencia desde 1941 y que suma 526 números, siendo el último en editarse en mayo-junio 2016; y la revista "La Antigua" editada por la Universidad Católica Santa María La Antigua que inició 1979 y suma 70 números.

La primera como fuente documental brinda la posibilidad de hacer varios análisis, puede ser abordada como una fuente de información primaria publicada pues en varios números se reprodujeron documentos parciales o completos tanto del AGI como el ANP o similares, o puede hacerse un análisis a nivel de representaciones de los indios y del occidente de Panamá, los temas tratados, los enfoques teóricos que se pueden ver reflejados, etc. Esta colección también es útil para rastrear la importancia o la ausencia de la historia indígena en el Panamá de los últimos 75 años. 
Voces, imágenes y escritos que rememoran el pasado... - A.S. Solano Acuña

La segunda revista consultada aun cuando no tiene tantos años de edición como primera, es un material interesante no solo por los datos que poseen algunos de sus trabajos publicados sino porque recupera una época (década de los setentas) donde la antropología y la arqueología sobre Panamá tuvo grandes aportes.

En cuanto a la prensa, predominó la "Estrella de Panamá", con temáticas sumamente variadas tales como el problema de límites entre Costa Rica y Colombia, misiones religiosas, las huacas de Chiriquí, enfrentamientos indígenas, entre otros. También se ubicaron noticias en "El Comercio de Perú" y "Daily Start and Herald". Cuando abordó el presente de los pueblos indígenas la gama de periódicos se amplió, aunque la "Estrella de Panamá" continúo siendo el principal generador de información. En cuanto a gacetas oficiales el tipo de información es variado, desde la transcripción de leyes y decretos, pasando por informes de prefectura, demandas y resoluciones indígenas, límites de Colombia y luego de Panamá, y la nacionalidad.

\subsection{El relato y la interpretación de la historia}

La fuente oral implica la documentación e información previa de la persona investigadora, con el fin de conducir a quien relata en la densidad de su memoria acerca de un evento, un personaje o de una fecha. La historia oral requiere un conjunto de fuentes históricas variadas, que permitan el contraste, la comparación, la confrontación, la confirmación.

El proceso se realiza mediante una entrevista semiestructura, que en ocasiones se ayuda de algunas fotografías, cartas o documentación variada localizada en archivo que se lleve a discusión y análisis. En muchas ocasiones el material al ser desconocido desata mucho interés, e incluso ha abierto la posibilidad a que una entrevista se convierta con cierta facilidad en un grupo de discusión al sumarse otras personas interesadas.

Los espacios de conversación se desarrollan en castellano, y se cuenta con la colaboración de una persona de la comunidad que hable la lengua indígena. Esto es especialmente útil con las personas colaboradoras que tienen más de 60 años y que con frecuencia hablan poco castellano o del todo no lo hablan.

En el caso de los registros orales, se ha tratado de asumir el proceso previo a la entrevista, así como su ejecución como un producto intelectual compartido. Esto es, el producto de una situación en la que se enfrentan dos universos ideológicos, culturales y sociales, pero a su vez buscan la inteligibilidad entre ambos.

Los relatores con quienes se trabajó fueron personas indígenas reconocidas por la comunidad como pensadores o especialistas. Principalmente, hombres mayores de 50 años, quienes a lo largo de su vida han desempeñado en el contexto comunitario un papel activo en el resguardo de la memoria colectiva y conocimientos propios. Cantores, curanderos, estudiosos de la lengua, historiadores por propia cuenta, 
maestros de cultura, en general personajes identificados por la comunidad como portavoces legítimos.

\section{PRINGIPALES APORTES A LA RECUPERACIÓN DE LA MEMO- RIA HISTÓRICA}

Los aportes del diseño e implementación una metodología propia para el estudio del pasado de esta sociedad indígena, han brindado varios aportes importantes destacando en primera línea la localización de documentación que sustenta las propuestas de etnoterritorialidad que se habían formulado en el pasado desde disciplinas como la arqueología o la antropología social.

Este hecho es de gran valor desde el presente y desde las actuales luchas ambientales y políticas porque sustenta, con documentos oficiales principalmente, la interconexión de un vasto territorio que cubría casi la mitad del actual territorio panameño a finales del siglo XIX basado en gran medida en el sistema de parentesco y la organización sociopolítica tradicional. Este etnoterritorio se encontraba muy lejos de la "tierra inhóspita" que reivindica la historiografía tradicional centroamericana para esta zona, pues dibuja un espacio geográfico que si bien mantenía una distancia de las administraciones centrales (durante al período colombiano y posterior a la independencia en 1903), también se encontraba interconectado como una necesidad para la resistencia. Ejemplo de ello son las demandas de los mismos sectores indígenas para la instalación de escuelas que les permitieran aprender el castellano; así como la demanda de autoridades locales por libros, prensa, constituciones, leyes, entre otras, herramientas todas para comprender la arena de negociación de las demandas por tierra, los impuestos y las legislaciones especiales para comunidades indígenas.

En un inmenso territorio como el descrito, también quedan evidenciados la diferencia interna y los vínculos profundos, que se activaron (y se activan) en momentos de crisis tales como las guerras o los desplazamientos. Las miradas de los viajeros por ejemplo ofrecen descripciones particulares, detalladas y minuciosas que retratan una sociedad indígena diversa internamente, riquísima y crítica de las situaciones que los afectaban.

Este último aspecto redimensiona la representación que se tenía de esta sociedad indígena en Costa Rica y Panamá, pues rescata a sus antepasados como colectivos que criticaban su lugar en el denominado "proyecto nacional", que hacían una valoración de sí y de sus otros culturales, que negociaban y que proponían. Es así como es posible acuñar la idea de una "cultura de resistencia" para esta sociedad indígena, entendida esta como una lucha activa (puede ser silenciosa y cotidiana) que tiene como propósito mantener los aspectos ideológicos, culturales y materiales para la reproducción de la filiación étnica.

Dentro de este marco activo, dentro de esta agencia constante, surgen del olvido los Gobernadores de indios, como personajes de quienes se conocía muy 
poco prácticamente nada para esta región y esta temporalidad. Estos fueron la pieza bisagra entre el sistema político republicano y la cultura política indígena, una de sus principales funciones consistió en amortiguar los efectos de la violencia y al expolio mediante el uso de la denuncia. Los Gobernadores de indios fueron hábiles comunicadores mediante memoriales e informes a las autoridades departamentales y nacionales de las prácticas de autoridades civiles en el nivel regional. Al ser el Gobernador de indios, por elección y no por linaje, llegó a encarnar la "causa común". Esta figura fue diferente a los "Reyes" o "Caciques Reyes" con quienes el Rey convivió, y a pesar de ser una figura que tiene sus orígenes en el período colonial y que fue impuesta, para el período de 1880-1925 se convirtieron en la desazón del régimen.

Los "modos de representación" coloniales plasmados en cada uno de los escritos, cartas, informes, entre otros; brindan retratos múltiples de la sociedad Guaymí, descubren a sus observadores y permiten acercarse a las relaciones de poder. El valor social de estudiar estas representaciones del pasado, radica en poner en perspectiva de larga duración las formas de representación cargadas de violencia, que se han hecho de las comunidades indígenas del occidente de Panamá. A lo largo de los 45 años en estudio, es posible observar como las representaciones de los indígenas Guaymí se iban transformando al calor del contexto político y de los intereses económicos aflorados sobre sus etnoterritorios.

Es así como a través de las representaciones surgidas de la memoria y las evocadas por el poder, se descubre a una sociedad indígena que evolucionó de una idea de "salvajes libres", a "indios pobres", a "grandes guerreros" y finalmente a "criminales encarnizados" y "peligro para la Nación" (Solano, 2019). Finalmente, en esta época se desarrolla la idea esencialista del "Guaymí verdadero", para evocar una condición folklórica y estática definida nuevamente desde los sectores de poder. Este mecanismo servirá durante todo el período (y hasta el presente) para negar derechos de autoidentificación, políticos y territoriales a ciertos sectores sociales.

\section{BIBLIOGRAFÍA}

Barabas, Alicia (2008). Cosmovisiones y etnoterritorialidad en las culturas indígenas de Oaxaca. Antípoda. Revista de antropología y arqueología. n. 7, pp. 119-139. DOI: https://doi.org/10.7440/antipoda7.2008.06

Consejo Nacional de Rectores (2016). Plan Nacional de la Educación Superior Universitaria Estatal 2016-2020. San José (Costa Rica): CONARE-OPES.

Das, Veena y Poole, Deborah (2008). El estado y sus márgenes. Etnografías comparadas. Cuadernos de Antropología Social, n. 27, pp. 19-52.

Howe, James (1996). Un pueblo que no se arrodilla. Panamá, los Estados Unidos y los Kunas de San Blas. Miami: Plumsock Mesoamerican Studies-CIRMA. 
Instituto Nacional de Estadística y Censos-Costa Rica (2013). X Censo Nacional de Población y VI de Vivienda: Territorios Indígenas. San José (Costa Rica): INE y Censos Costa Rica.

Instituto Nacional de Estadística y Censos-Panamá (2010). Diagnóstico de la población indigena en Panamá. San José (Costa Rica): INE y Censos Costa Rica.

Jelin, Elizabeth (2002). Los trabajos de la memoria. Madrid: Siglo XXI.

Pérez Brignoli, Héctor (2010). Breve historia de Centroamérica. Madrid: Alianza.

Pizzurdo Gelós, Patricia y Arauz, Celestino (1996). Estudios sobre el Panamá Republicano (1903-1989). Bogotá: Manfer.

Roulet, Florencia y Navarro Floria, Pedro (2005). De soberanos externos a rebeldes internos: la domesticación discursiva y legal de la cuestión indígena en el tránsito del siglo XVIII al XX. Revista TEFROS, n. 1, pp. 1-41.

Sandner, Gerhard (1981). Estructuración espacio-político-geográfica y la geopolítica en la Región Caribe. Revista geográfica de América Central, n. 13-14, pp. 41-66.

Sandner, Gerhard (2003). Centroamérica y el Caribe occidental: coyunturas, crisis y conflictos 1503-1984. Bogotá: Universidad Nacional de Colombia.

Santana Cardoso, Ciro y Pérez Brignoli, Héctor (1999). Economías de exportación y economía capitalista. En Santana Cardoso, Ciro y Pérez Brignoli, Héctor (eds). Historia Económica de América Latina. Barcelona: Crítica.

Serrano Álvarez, Pablo (2002). Historiografía regional y local mexicana, 1968-2000. Diversidad y pluralidad de tendencias. Diálogos Latinoamericanos, n. 5, pp. 99108.

Solano Acuña, Ana Sofía (2019). Imágenes de la memoria y el poder. Los Guaymí del occidente de Panamá en la conformación del Estado Nacional (1880-1925) (Tesis doctoral). Universidad Pablo de Olavide, Sevilla (España).

Soto Quirós, Ronald y Díaz Arias, David $(\uparrow \cdot 6)$. Mestizaje, indigenas e identidad nacional en Centroamérica: De la Colonia a las Repúblicas Liberales. San José, Costa Rica: Sede Académica, Costa Rica, Facultad Latinoamericana de Ciencias Sociales (FLACSO).

Taracena Arriola, Arturo (1999). Región e historia. Desacatos, n. 1, pp. 1-8. 
